\title{
Bacterial etiology of acute otitis media among children attending Khartoum Ear Nose Throat Teaching Hospital in 2014
}

\author{
Mogadam Baher Eldin Mogadam Yagob ${ }^{1 \star}$ and Siham Mohammed Sulieman ${ }^{2}$ \\ ${ }^{1}$ Department of Medical Laboratory Sciences, University of Medical Sciences and Technology, Mecca Street, Al Riyadh, \\ Khartoum, Sudan. \\ ${ }^{2}$ University of Medical Sciences and Technology, Mecca Street, Al Riyadh, Khartoum, Sudan.
}

Accepted 23 May, 2017

\begin{abstract}
Acute otitis media (AOM) is occasionally caused by Eustachian tube dysfunction and obstruction; it is second most common disease in children. The objective of this study is to determinate and isolate the causative agents of $\mathrm{AOM}$ among children and antimicrobial susceptibility pattern to certain antibiotics. A cross sectional hospital based study on 100 acute otitis media patients seen in Khartoum Ear Nose throat Teaching hospital. Patients' information was collected using pre-structural questionnaire. Ear swabs were collected from discharging ears and processed for bacteria culture and susceptibility to different antimicrobial agent using standard microbiological techniques. Out of 100 ear swabs collected and processed through standard microbiological techniques, 68 (total number of culture plate) were culture positive and 32 were negative for bacterial growth. The most common isolated microorganism was Staphylococcus aureus 38 (from total number of isolated organism $=78$ ) $(48.7 \%)$, followed by Pseudomonas aeruginosa 15 (19.2\%), Escherichia coli 4 (5.1\%), Citrobacter freundii 8 (10.3\%), Morgenalla morganii 9 (11.5\%) and Edwardsiella tarda 4 (5.1\%). All isolates were resistant to Ampicillin (100\%). Almost all isolated bacteria were sensitive to two or more antibiotics. About $6(15.8 \%)$ of $S$. aureus were resistant to Methicillin. In conclusions, $S$. aureus was the major isolated bacteria, about (15.8\%) of $S$. aureus are Methicillin resistance that cause acute otitis media. Ciprofloxacin, Ceftazidime, Gentamicin and Ceftriaxone were relatively effective antibiotics. However, all isolates showed multi drug resistance to the Ampicillin.
\end{abstract}

Keywords: Acute otitis media, Khartoum Ear Nose Throat teaching hospital, antibiotic resistance.

*Corresponding author. E-mail: mogadam.baher@umst-edu.sd, smsulieman@gmail.com. Tel: 00249960101112, 00249912337876.

\section{INTRODUCTION}

Acute otitis media (AOM) is occasionally caused by Eustachian tube dysfunction and obstruction, it is second most common disease in children, about $75 \%$ of children have at least one case by one year of age because Eustachian tube are shorter and more horizontal can be easily to obstruction by enlarged adenoids (Forgie et al., 2009). It is the infection of the middle ear association with acute signs and symptoms; it produces fluid more likely to be opaque and tympanic membrane maybe red or dark yellow or bulging (Forgie et al., 2009). Middle ear cavity is normally a sterile compartment, which is maintaining by the mucociliary system together with the enzymes and antibodies secreted by the epithelial cells of the Eustachian tube (ET) and the middle ear. Abnormal anatomy and dysfunction of the tube are involved in the development of AOM. An infection in the nasopharynx and ET lead to increased mucous secretion that can obstruct the ET resulting in a negative middle ear pressure and the bacteria can then enter the middle ear (Kaltes, 2003). The most causative agent of AOM are bacteria about $60 \%$ from all cases, the bacterial organism that are most commonly causing AOM are Streptococcus pneumoniae also called (S. pneumoniae or pneumococcus), Haemophilus influenzae, Moraxella 
catarrhalis, Streptococcus pyogenes, Staphylococcus aureus and Pseudomonas spp (Simon, 2009; Seid et al., 2013).

The objective is to Isolate the causative agents of AOM among children and determine their susceptibility to certain antimicrobial pattern.

\section{MATERIALS AND METHODS}

\section{Study design}

A cross section hospital based study at Khartoum Ear Nose Throat Teaching Hospital (ENT). The children under 12 year of age were visited the ENT outpatient department for AOM during the period from January to April 2014 and for whom a middle ear fluid samples were enrolled in the study. Patients who on antimicrobial drugs or onset of signs and symptoms persist more than 2 weeks, criteria to sample collection were excluded from study.

The patient referred to 100 ear swabs were collected using a sterile cotton swab under good light and aseptic technique. From each patient was taken two ear swab; one kept in Amie's transport media and other swab was processed immediately through microbiological techniques for isolation and identification of bacteria by Gram stain and biochemical test (Indole test, Urea hydrolysis test, Motility, Citrate utilization test, Kligler's Iron Agar and Oxidase test for Gram-negative bacteria while Catalase test, Coagulate test and DNA-ase test for Gram positive) (Seid et al., 2013; Cheesbrough, 2006).

All the swabs were inoculated on $5 \%$ Blood agar and Chocolate blood agar under aerobic, 5 to $10 \%$ carbon dioxide and anaerobic conditions and on MacConkey, agar plate (Himedia Company, India) was incubated in aerobic condition at 37 overnight (18 to 24 h). Isolation and identification of bacteria was done through the application of the standard microbiological methods (Seid et al., 2013; Cheesbrough, 2006; Leboffe and Pierce, 2011).

\section{Drug susceptibility testing}

Antimicrobial susceptibility was done by Modified disc diffusion method using certain type of antibiotic discs used for acute otitis media. These include Amikacin $(10 \mathrm{mcg})$, Gentamicin $(10 \mathrm{mcg})$, Ciprofloxacin $(5 \mathrm{mcg})$, Ampicillin $(10 \mathrm{mcg})$, Co-Trimoxazole (25 $\mathrm{mcg}$ ), Ceftazidime (30 mcg), Meropenem (10 mcg), Oxacillin (10 $\mathrm{mcg}$ ), Ceftriaxone $(30 \mathrm{mcg})$ and Vancomycin $(30 \mathrm{mcg})$ (Himedia, India).

Suspend the organism in $2 \mathrm{ml}$ of sterile saline and compare it with turbidity standard (0.5 McFarland standard) Inoculate into dried surface of a Mueller-Hinton (MH) agar plate by using sterile cotton swab then, Place the appropriate antimicrobial-impregnated disks on the surface of the agar (Hudzicki, 2009).Then, incubated aerobically at $37^{\circ} \mathrm{C}$ for 16 to $18 \mathrm{~h}$ exception for Oxacillin (extended for $24 \mathrm{~h}$ because required more time to confirm the result) (Seid et al., 2013). Zone of inhibition was measured in $\mathrm{mm}$ and interpreted as sensitive, intermediate and resistant depend on chart standard break point extracted from CLSI (The Clinical and Laboratory Standards Institute) and compare the inhibition zone with control strains Escherichia coli (ATCC25922), Staphylococcus aureus (ATCC 25923) and Pseudomonas aeruginosa (ATCC 27853) (Cockerill, 2013).

\section{Data analysis}

The data were processed and formulated using Microsoft Excel version 2007. Frequency tables were interpreted using Statistical Package for Social Sciences (SPSS) version 16.0 software computer package.

\section{Ethical consideration}

Sudan Medical and Scientific Research Institute (SUMASRI) and Institutional Review Board (SIRB) approved this research.

\section{RESULTS}

Out of 100 ear swabs collected and processed through standard microbiological techniques, 68 were culture positive and 32 were negative for bacterial growth. The pure culture was identified in 58 (84.3\%) clinical specimens while $10(14.7 \%)$ clinical specimens showed mixed population of bacteria (Table 1). The overall bacterial detection rate was 78 . Thirty-eight of $78(48.7 \%)$ isolated bacteria were Gram-positive cocci, while 40 (51.3\%) Gram-negative bacilli (Table 2 ). The most common isolated microorganism was Staphylococcus aureus 38 (48.7\%), followed by Pseudomonas aeruginosa 15 (19.2\%), Escherichia coli 4 (5.1\%), Citrobacter freundii 8 (10.3\%), Morgenalla morganii 9 (11.5\%) and Edwardsiella tarda 4 (5.1\%) (Table 3).

Antimicrobial sensitivity tests indicated that the most effective drugs for all Gram-negative isolates $100 \%$ were sensitive to Gentamicin, Ciprofloxacin and Amikacin followed by Co-Trimoxazole (36\%) However, $P$. aeruginosa showed $100 \%$ sensitivity to Meropenem. The Gram positive were found to be sensitive $100 \%$ to Gentamicin (local guideline for treating AOM), Ceftriaxone, and Vancomycin and followed by Oxacillin (84.4\%). All Gram-negative bacteria isolated were resistant to Ampicillin. Six (15.8\%) Staphylococcus aureus were Methicillin Resistant which caused acute otitis media (Table 4).

\section{DISCUSSION}

The present study showed that, 68 of acute otitis media patient caused by bacteria, while 32 showed no growth (this may be due to viral infection). The predominant isolates were $S$. aureus, which accounted for $38(48.7 \%)$ followed by $P$. aeruginosa $15(19.2 \%)$, Escherichia coli 4 $(5.1 \%)$, Citrobacter freundii $8(10.3 \%)$ as coliform and these findings were agreed with the studies of Seid et al. in North East Ethiopia (2013) and Hussain et al. (1991).

The variation in isolation rate of these organisms may be due to differences in the locality of study area and in population immunity.

Morgenalla morganii 9 (11.5\%) and Edwardsiella tarda $4(5.1 \%)$ in spite that the two organisms are not considered as a commonly causative agent of AOM.

All the Gram negative bacilli showed sensitive to Gentamicin, Ciprofloxacin and Amikacin followed by Co- 
Table 1. Mix bacterial infection isolate about 10 (14.7\%).

\begin{tabular}{lc}
\hline Type of mix bacteria & Number of mix (\%) \\
\hline Staphylococcus aureus + Citrobacter freundii. & $2(20)$ \\
Edwardsiella tarda + Citrobacter freundii. & $4(40)$ \\
Staphylococcus aureus + Escherichia coli. & $4(40)$ \\
\hline
\end{tabular}

Table 2. Biochemical tests used for identification of GNB.

\begin{tabular}{|c|c|c|c|c|c|c|c|c|c|}
\hline \multirow{2}{*}{$\begin{array}{c}\text { Oxidase } \\
\text { test }\end{array}$} & \multirow{2}{*}{$\begin{array}{c}\text { Citrate } \\
\text { utilizing test }\end{array}$} & \multirow{2}{*}{$\begin{array}{c}\text { Urease } \\
\text { test }\end{array}$} & \multirow{2}{*}{$\begin{array}{c}\text { Indole } \\
\text { test }\end{array}$} & \multirow{2}{*}{$\begin{array}{c}\text { Motility } \\
\text { test }\end{array}$} & \multicolumn{4}{|c|}{ KIA } & \multirow{2}{*}{ Suggested organisms } \\
\hline & & & & & Slope & Butt & $\mathrm{H}_{2} \mathrm{~S}$ & Gas & \\
\hline+ & + & + & - & + & $\mathrm{R}(-)$ & $\mathrm{R}(-)$ & - & - & Pseudomonas aeruginosa \\
\hline- & + & - & - & + & $R(-)$ & $Y(+)$ & + & + & Citrobacter freundii \\
\hline- & - & - & - & + & $Y(+)$ & $Y(+)$ & - & - & Escherichia coli \\
\hline- & - & - & + & + & $R(-)$ & $\mathrm{Y}(+)$ & + & - & Edwardsiella tarda \\
\hline- & - & + & + & + & $Y(+)^{*}$ & $Y(+)$ & - & - & Morgenalla morganii \\
\hline
\end{tabular}

Key: KIA: Kligler's Iron Agar, +: positive, - : negative, R (+) : Red color without acid production, Y (+): Yellow color related to acid production), red or yellow colors depend on $\mathrm{pH}$ indicator was used in the growth medium (Phenol Red)), ": origin bacteria cannot ferment the lactose but, now become lactose fermenting, H2S: Hydrogen Sulphide test (blacking), butt: bottom part of tube, Slope above part of tube.

Table 3. Type and frequency of bacterial isolated pure and mix culturing.

\begin{tabular}{lcc}
\hline Organisms isolated & Frequency & Percent \% \\
\hline Staphylococcus aureus & 38 & 48.7 \\
Citrobacter freundii & 8 & 10.3 \\
Edwardsiella tarda & 4 & 5.1 \\
Morgenalla morganii & 9 & 11.5 \\
Escherichia coli & 4 & 5.1 \\
Pseudomonas aeruginosa & 15 & 19.2 \\
Total & 78 & 100 \\
\hline
\end{tabular}

Table 4. Sensitivity of Antibiotic pattern of bacterial isolated from acute otitis media patient.

\begin{tabular}{|c|c|c|c|c|c|c|c|c|c|}
\hline \multirow{2}{*}{ Bacterial species (of isolates) } & \multicolumn{9}{|c|}{ Drugs sensitized \% (Antibiotics use ) } \\
\hline & AMK & $\mathbf{M}$ & CIP & AMP & COT & GN & CFT & OX & V \\
\hline Citrobacter freundii & 100 & - & 100 & 0 & 0 & 100 & - & - & - \\
\hline Edwardsiella tarda & 100 & - & 100 & 0 & 0 & 100 & - & - & - \\
\hline Morgenalla morganii & 100 & - & 100 & 0 & 88.8 & 100 & - & - & - \\
\hline Escherichia coli & 100 & - & 100 & 0 & 25 & 100 & - & - & - \\
\hline Pseudomonas aeruginosa & 100 & 100 & 100 & 0 & - & 100 & - & - & - \\
\hline Staphylococcus aureus & - & - & - & 0 & - & 100 & 100 & 84.2 & 100 \\
\hline
\end{tabular}

Key: $\mathrm{AMK}=$ Amikacin $(10 \mathrm{mg}), \mathrm{GN}=$ Gentamicin $(10 \mathrm{mg}), \mathrm{CIP}=$ Ciprofloxacin $(5 \mathrm{mg}), \mathrm{AMP}=$ Ampicillin $(10 \mathrm{mg})$, COT = Co-Trimoxazole $(25 \mathrm{mg})$, CAZ = Ceftrazidine $(30 \mathrm{mg}), \mathrm{M}=$ Meropenem $(10 \mathrm{mg}), \mathrm{OX}=$ Oxcillin $(10 \mathrm{mcg}), \mathrm{CFT}=$ Ceftriaxone $(30 \mathrm{mg}), \mathrm{V}=\mathrm{Vancomycin}(30 \mathrm{mg}), \mathrm{KF}=$ Cephalothin (30 mg), "-": the antimicrobial did not.

Trimoxazole (36\%) some of these agree with Seid et al. (2013). Meropenem were also sensitive to $P$. aeruginosa. While the Gram positive were found to be sensitive 100\% to Gentamicin, Ceftriaxone and Vancomycin and followed by Oxacillin (84.4\%).

All Gram-negative bacteria (GNB) isolated were resistant to Ampicillin; this finding in agree with that reported by Seid et al. (2013).

The best antimicrobials were selected with regard to sensitivity for Gram-positive and Gram-negative organisms; and Gentamicin can be considered as drug of choice for treatment of acute otitis media. 
In German where Haemophilus influenzae, Streptococcus pneumoniae, Streptococcus pyogenes and Moraxella catarrhalis were most frequent isolated reported by Grevers et al. (2012), and a study in Mexican Streptococcus, pneumoniae and Haemophilus influenza were the dominant isolated by Parra et al. (2011), reported that the organisms isolated was mainly etiology case AOM in US and Europe, however in tropical area and Latin America are limited.

The swabs were transported to the lab and kept in Amie's transport media reported by Seid et al. (2013). However, in this study, there is no difference when put in transport media or without it.

\section{Conclusions}

i) About 6 (15.8) of Staphylococcus aureus are Methicillin resistant.

ii) Gentamicin (100\%), Amikacin (100\%) and Ciprofloxacin (100\%) were the most effective drugs against Gram-negative organism.

iii) Gentamicin, Ceftriaxone, Vancomycin and followed by Oxacillin (84.4\%). were the most sensitive drugs against Gram-positive organisms.

iv) Staphylococcus aureus was the predominant isolate.

v) Gentamicin as drug of choice for treatment of acute otitis media.

\section{RECOMMENDATIONS}

i) Ear swabs from acute otitis media should be sent as soon as possible to the laboratory; transport media are not necessary.

ii) Direct Gram stain from the sample is very important, which provide primary guideline to identify the causative agent.

iii) Culturing and identification of samples in the laboratory is very important because of the emergence of organism that is considered as causative agent of AOM and presence of MRSA.

iv) It treatment to be given without lab diagnosis the drug of choice should be topical or both systemic and topical Gentamicin because all bacteria are sensitive to it.

\section{Limitations of the study}

i) Short duration of study due to regulation of university.

ii) Fungi and viruses are not included because due to limit of availability of material.

iii) Erythromycin and tetracycline are not included.

iv) Limited biochemical laboratory tests may cause misidentifications but, here, any potential misidentification does not affect clinical usefulness of this study.

\section{REFERENCES}

Cheesbrough M, 2006. District Laboratory Practice in Tropical Countries, part 2. $2^{\text {nd }}$ Edition, Cambridge, Cambridge University Press, 62-70.

Cockerill RF, Patel BJ, Alder J, Bradford AP, Dudley NM, Eliopoulos MG, Hardy DJ, Hecht DW, Hindler JA, Powell M, Swenson JM, Thomson RB, Traczewski MM, Turnidge JD, Weinstein MP, Zimmer BL, 2013. Performance Standards for Antimicrobial Susceptibility Testing; Twenty-Third Informational Supplement. CLSI. 32. 3.

Forgie S, Zhanel G, Robinson J, 2009. Managment of acute otitis media. Can Paediatr Soc, 14(7): 457-460.

Grevers G, Wiedemann S, Bohn J, Blasius R, Harder T, Kroeniger W, Vetter V, Pirçon J-Y, Marano C, 2012. Identification and characterization of the bacterial etiology of clinically problematic acute otitis media after tympanocentesis or spontaneous otorrhea in German children. BMC Infect Dis, 12, 312.

Hudzicki J, 2009. Kirby-Bauer Disk Diffusion Susceptibility Test Protocol [serial online]. [cited 2014 March 30]; Available from: URL:http://www.microbelibrary.org/component/resource/laboratorytest/3189-kirby-bauer-disk-diffusion-susceptibility-test-protocol.

Hussain MA, Ali EM, Ahmed HS, 1991. Otitis media in Sudanese children. East Afr Med J, 68(9): 679-685.

Kaltes GAB, 2003. Experimental Acute Otitis Media [serial online]. [cited 2014 February 18]; Available from: URL: http://www.divaportal.org/smash/get/diva2:141575/FULLTEXT01.pdf.

Leboffe JM, Pierce EBA, 2011. Photographic Atlas for the Microbiology Laboratory, 4th Edition, United States of America, Morton Publishing Company, pp: 8-96.

Parra MM, Aguilar GM, Echaniz-Aviles G, Rionda RG, Estrada ML, Cervantes Y, Pirçon JY, Van Dyke MK, Colindres RE, Hausdorff WP, 2011. Bacterial etiology and serotypes of acute otitis media in Mexican children. Vaccine, 29(33): 5544-5549.

Seid A, Deribe F, Ali A, Kibru G, 2013. Bacterial otitis media in all age group of patients seen at Dessie referral hospital, North East Ethiopia. Egypt J Ear Nose Throat Allied Sci, 14(2): 73-78.

Simon H, 2009. Ear infections [serial online]. [cited 2014 February 24]; Available from: URL: http://adam.about.net/reports/Ear-infections. htm.

Citation: Yagob MBEM, Sulieman SM, 2017. Bacterial etiology of acute otitis media among children attending Khartoum Ear Nose Throat Teaching Hospital in 2014. M icrobiol Res Int, 5(2): 25-29. 
Table 5. Zone size interpretative chart standard break point extracted from CLSI (The Clinical and Laboratory Standards Institute) (Cockerill 2013).

\begin{tabular}{llcl}
\hline Antibiotics & Resistant & Intermediate & Sensitive \\
\hline Amikacin $(30 \mathrm{mcg})$ & Less than 14 & $15-16$ & More than 17 \\
Gentamicin $(10 \mathrm{mcg})$ & Less than 12 & $13-14$ & More than 15 \\
Ciprofloxacin $(5 \mathrm{mcg})$ & Less than 15 & $16-20$ & More than 21 \\
Ceftriaxone $(30 \mathrm{mcg})$ & Less than 13 & $14-20$ & More than 21 \\
Co-Trimoxazole $(25 \mathrm{mcg})$ & Less than 10 & $11-15$ & More than 16 \\
Ceftrazidime $(30 \mathrm{mcg})$ & Less than 14 & $15-17$ & More than 18 \\
Meropenem $(10 \mathrm{mcg})$ & Less than 13 & $14-15$ & More than 16 \\
Oxcillin $(1 \mathrm{mcg})$ & Less than 10 & $11-12$ & More than 13 \\
Penicillin $(10 \mathrm{units})$ & Less than 28 & - & More than 29 \\
Vancomycin $(30 \mathrm{mcg})$ & Less than 14 & $15-16$ & More than 17 \\
Ampicillin $(10 \mathrm{mcg})$ & Less than 13 & $15-16$ & More than 17 \\
Cephalothin $(30 \mathrm{mg})$ & Less than 20 & $21-27$ & More than 28 \\
\hline
\end{tabular}

